\title{
Voltage-Gated Potassium Channels: A Structural Examination of Selectivity and Gating
}

\author{
Dorothy M. Kim and Crina M. Nimigean \\ Department of Anesthesiology, Weill Cornell Medical College, New York, New York 10065 \\ Correspondence: dok2004@med.cornell.edu
}

Voltage-gated potassium channels play a fundamental role in the generation and propagation of the action potential. The discovery of these channels began with predictions made by early pioneers, and has culminated in their extensive functional and structural characterization by electrophysiological, spectroscopic, and crystallographic studies. With the aid of a variety of crystal structures of these channels, a highly detailed picture emerges of how the voltage-sensing domain reports changes in the membrane electric field and couples this to conformational changes in the activation gate. In addition, high-resolution structural and functional studies of $\mathrm{K}^{+}$channel pores, such as KcsA and MthK, offer a comprehensive picture on how selectivity is achieved in $\mathrm{K}^{+}$channels. Here, we illustrate the remarkable features of voltage-gated potassium channels and explain the mechanisms used by these machines with experimental data.

\section{INTRODUCTION TO $\mathrm{K}^{+}$CHANNELS}

Electrical signaling is produced by the interEplay of a diverse array of ion channels, which are elegantly orchestrated to respond to a variety of stimuli and propagate this response in an efficient manner. Channel opening and closing is exquisitely balanced among different types of channels to correctly and precisely maintain homeostasis at resting potential and contribute to explosive electrical activity during the action potential. Potassium channels play a role in repolarization of the membrane, which follows membrane depolarization by sodium, and in some cases calcium, channels during the action potential; this is necessary for returning the membrane to a negative resting potential to terminate the action potential signal. The balance required for this interplay is achieved through the extremely high ionic selectivity, high rate of flux, and sophisticated gating mechanisms of potassium channels.

Potassium channels are found in all living organisms. These highly selective channels are conserved across the kingdoms and are present in all cell types including neurons, muscle cells, and other tissues. They have evolved to play different roles in different cells, yet they have retained key features that are conserved throughout the potassium channel family. One universal trait is their high selectivity; some potassium channels show up to 1000fold preference for $\mathrm{K}^{+}$ions, over smaller ions such as $\mathrm{Na}^{+}$and $\mathrm{Li}^{+}$(Yellen 1984; Neyton and Miller 1988a; Hille 2001; LeMasurier et al. 2001). This high degree of selectivity is necessary for maintaining the resting membrane potential, with high $\mathrm{K}^{+}$inside and high $\mathrm{Na}^{+}$out-

Editors: Paul J. Kammermeier, Ian Duguid, and Stephan Brenowitz

Copyright (C) 2016 Cold Spring Harbor Laboratory Press; all rights reserved; doi: 10.1101/cshperspect.a029231 Cite this article as Cold Spring Harb Perspect Biol 2016;8:a029231 
D.M. Kim and C.M. Nimigean

side of the cell. This selectivity is achieved by the structure of a highly conserved amino acid sequence that forms a potassium ion selectivity filter within the pore.

The membrane permeability of excitable cells to potassium ions was predicted by Julius Bernstein in 1902 (Bernstein 1902). He hypothesized that cells at rest were exclusively permeable to $\mathrm{K}^{+}$ions and that the cells were permeable to other ions only during periods of excitation, suggesting that there existed ionselective components in the membrane. This hypothesis was borne out through the breakthrough studies by Hodgkin and Huxley performed on the squid giant axon in the 1940s and 1950s, which characterized the action potential in terms of the coordinated changes in the cell membrane permeability to $\mathrm{Na}^{+}$and $\mathrm{K}^{+}$ions and developed a model directly correlating these fluxes with excitation and electrical conduction (Goldman 1943; Hodgkin and Huxley 1945, 1946, 1947, 1952a,b,c,d,e,f; Hodgkin and Katz 1949; Hodgkin et al. 1952; Hodgkin and Keynes 1955). This was correctly hypothesized at the time to result from the orchestrated opening and closing of voltagedependent ion-selective channels. Their exper- iments confirmed that the cell was predominantly selective for $\mathrm{K}^{+}$ions when it was at rest, resulting in a negative transmembrane potential (measured as the inside of the cell relative to the outside). These studies were key in highlighting the importance of both ion selectivity and regulated gating to generation of the action potential.

In addition to being highly selective, $\mathrm{K}^{+}$ channels conduct ions at an extremely fast rate, close to the rate of diffusion (Hille 2001). How is this possible? Again, the clever architecture of the selectivity filter provides the answer to this paradox. Structural and functional studies of potassium channels have shown that the placement of ions in the selectivity filter leads to a "knock-on" mechanism (Fig. 1), which exploits the charge-charge repulsion of the $\mathrm{K}^{+}$ ions that march in single file through the filter (Hodgkin and Keynes 1955; Doyle et al. 1998). Thus, the selectivity filter has evolved to efficiently conduct ions in a highly selective manner, allowing the fast rate of flux required to quickly repolarize the cell.

$\mathrm{K}^{+}$channels must respond rapidly on sensing changes in cellular environment. Ion flux is controlled by channel gating; that is, the ions
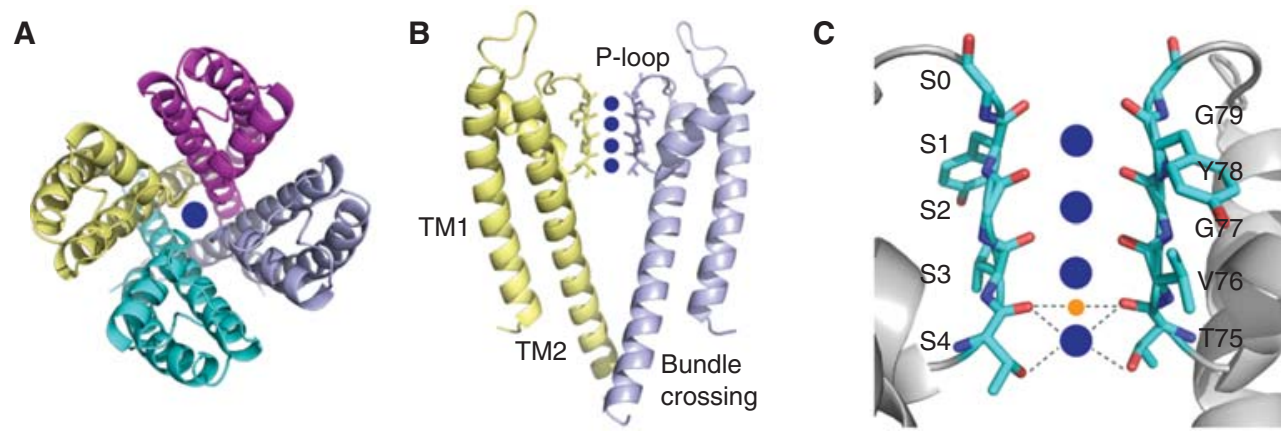

Figure 1. Structural details of KcsA. (A) KcsA tetramer as viewed from the top of the membrane (PDBID:14KC). Each subunit is uniquely colored. The central ion conduction pore is shown with a $\mathrm{K}^{+}$ion (blue sphere). (B) KcsA as viewed from the side with two opposing subunits removed for clarity. The P-loop contains the signature sequence TVGYG (shown as sticks), and forms the selectivity filter. Four potassium ions are shown in the selectivity filter. Below the selectivity filter is the aqueous cavity, formed by the TM2 helices that form the bundle crossing. $(C)$ A detailed view of the selectivity filter of KcsA. Each binding site, S0-S4, is formed by the oxygen cages originating from backbone carbonyl and side-chain hydroxyls of the selectivity filter signature sequence TVGYG. Dashed lines depict coordination of the $\mathrm{K}^{+}$ion in $\mathrm{S} 4$ and the oxygens. Sodium (orange sphere) binds in the plane between sites S3 and S4. Dashed lines represent its coodination with carbonyl oxygens. 
Voltage-Gated Potassium Channels

cannot pass through the selectivity filter unless the channel is open, and the flow of ions must also be controlled by the ability of the channel to close. To do this rapidly, potassium channels have evolved gating mechanisms to couple the sensing of environmental cues with physical movements of domains within the channel that control ion flux. A major family of potassium channels is the voltage-gated potassium channels $(\mathrm{Kv})$, which detect changes in transmembrane voltage and couple this detection to channel opening and closing.

Here, we will discuss the mechanisms by which $\mathrm{K}^{+}$channels achieve high selectivity while retaining a fast rate of flux, how the channel senses the change in transmembrane voltage, and how this detection of voltage is coupled to gating of the channel.

\section{$\mathrm{K}^{+}$CHANNEL SELECTIVITY}

The puzzle of ion selectivity was pieced together by ingenious predictions of the pore characteristics by pioneers in the ion channel field. Important findings included pore size, ion dehydration as a requirement for pore entry, and the existence of stabilizing interactions between the pore walls and the ion (Mullins 1959; Eisenman 1962; Bezanilla and Armstrong 1972; Hille 1975a,b). In addition, Bezanilla and Armstrong (1972) and Hille (1973) proposed that $\mathrm{K}^{+}$ions were stabilized inside the pore of the $\mathrm{K}^{+}$channel by specific binding sites, which were composed of oxygen dipoles forming a "bracelet," and that this region would consist of a cylindrical pore with an inner diameter of 3-3.4 $\AA$. The identification of a signature amino acid sequence, highly conserved among $\mathrm{K}^{+}$-selective channels, provided a hypothesis for the identity of the $\mathrm{K}^{+}$channel selectivity filter, and subsequent functional studies confirmed that mutation of this signature sequence disrupts $\mathrm{K}^{+}$selectivity (Heginbotham et al. 1992, 1994). The culmination of our understanding of the selectivity filter arrived with the crystal structure of the KcsA potassium channel, which confirmed all of these predictions based on functional data with structural data (Doyle et al. 1998; Zhou et al. 2001b). The structure shows the selectivity filter to be a narrow pore with dimensions of $\sim 3 \AA$, with specific potassium binding sites formed by carbonyl oxygen atoms from residues in the signature sequence TVGYG (Fig. 1) (Heginbotham et al. 1994).

The requirement for specific binding sites to stabilize $\mathrm{K}^{+}$ions in the $\mathrm{K}^{+}$channel selectivity filter seemed to be in direct contrast to the fast flux rates measured in $\mathrm{K}^{+}$channels. Notably, Bezanilla and Armstrong suggested that the result of high selectivity would be slow permeation (Bezanilla and Armstrong 1972); however, the large conduction rates of potassium channels contradict this suggestion. This paradox led to the proposal of the multi-ion theory by several groups (Hodgkin and Keynes 1955; Heckmann 1965a,b, 1968, 1972; Hille and Schwarz 1978), which was supported by the following studies. Hodgkin and Keynes explained anomalous unidirectional flux ratios in squid axons by proposing that multiple ions pass through long pores in single file (Hodgkin and Keynes 1955). In addition, changes in permeability ratios in different ion-selective channels in the presence of more than one permeant ion (the anomalous mole fraction effect), could only be explained by the interaction of at least two ions within the pore (Chandler and Meves 1965; Hagiwara and Takahashi 1974; Neher and Sakmann 1975; Cahalan and Begenisich 1976; Sandblom et al. 1977; Hille and Schwarz 1978; Begenisich and Cahalan 1980; Almers and McCleskey 1984; Hess and Tsien 1984; Eisenman et al. 1986). Amazingly, these predictions were later confirmed by structural studies of potassium channels, which showed multiple ions occupying the selectivity filter pore.

Structural studies of potassium channels were made possible by the emergence of recombinant DNA technology in the 1980s, accelerating the ability to study these channels in isolation. Following cloning of the nicotinic acetylcholine receptor channel nAChR from Torpedo californica (Noda et al. 1982, 1983) and the voltage-gated sodium channel from the electric eel Electrophorus electricus (Noda et al. 1984), the first potassium channel was discovered by the analysis of Drosophila mutants. One of these mutants showed uncontrol- 
D.M. Kim and C.M. Nimigean

lable shaking, leading to the identification of the Shaker locus (Papazian et al. 1987). This gene was the first $\mathrm{K}^{+}$channel to be cloned and encodes a member of the voltage-gated potassium channel (Kv) family. Functional studies with Shaker revealed incredible insight into $\mathrm{K}^{+}$channel selectivity, including its preference for $\mathrm{K}^{+}$, $\mathrm{Rb}^{+}$, and $\mathrm{NH}_{4}^{+}$over $\mathrm{Na}^{+}$(Heginbotham and MacKinnon 1993). The cloning of Shaker, along with cloning of additional potassium channels, enabled taxonomic grouping of channels into functional superfamilies by sequence analysis. These analyses led to the discovery of the "signature sequence" of the selectivity filter, which contains the super conserved GYG motif that serves as the basis for ion selectivity in $\mathrm{K}^{+}$channels (Heginbotham et al. 1994) (exceptions are the EAG-like $\mathrm{K}^{+}$channels and the inwardly rectifying Kir6 family of $\mathrm{K}^{+}$channels, which contain the sequence GFG).

The discovery of homologous potassium channels in prokaryotic organisms catapulted the ion channel field into the structural era, with the crystal structure of the bacterial potassium channel KcsA from Streptomyces lividans, providing a rich understanding of fundamental properties of ion channels (Doyle et al. 1998; LeMasurier et al. 2001; Zhou et al. 2001b). KcsA was revealed to be a tetramer with fourfold symmetry, containing a pore formed by each subunit along the axis of symmetry (Fig. 1A). The transmembrane region of each subunit consists of two transmembrane domains TM1 and TM2. An extracellular loop, called the turret, followed by a short helix, called the pore helix, link these two helices (Fig. 1B). The carboxyl terminus of this pore helix extends toward the center of the channel pore, and precedes the signature sequence $\mathrm{T}_{75} \mathrm{~V}_{76} \mathrm{G}_{77} \mathrm{Y}_{78} \mathrm{G}_{79}$, located on the P-loop (Fig. 1B,C). The P-loop forms the selectivity filter by extending toward the extracellular end of the channel and creating a narrow pore. Importantly, the oxygens of the backbone carbonyls of residues Y78, G77, V76, and T75 as well as from the side-chain hydroxyl of T75 point directly toward the center of the fourfold symmetric pore. These oxygens from four identical subunits form four cages or $\mathrm{K}^{+}$binding sites, numbered $\mathrm{S} 1-\mathrm{S} 4$, which co- ordinate dehydrated $\mathrm{K}^{+}$in single file during permeation. Each $\mathrm{K}^{+}$ion is surrounded by eight oxygen atoms, mimicking $\mathrm{K}^{+}$hydration in solution (Fig. 1C). This region forms the narrowest part of the pore with dimensions of $\sim 3 \AA$, strikingly similar to the predicted 3-3.4 $\AA$ from earlier functional studies (Bezanilla and Armstrong 1972; Hille 1973). The backbone carbonyls of Y78 and G77 form S1, the most extracellular $\mathrm{K}^{+}$binding site, whereas the side-chain hydroxyl and backbone carbonyl oxygens of T75 form S4, the most intracellular binding site. Additionally, the crystal structure reveals a fifth binding site for $\mathrm{K}^{+}$at the extracellular surface of the channel, S0, which is coordinated by the backbone carbonyl oxygens of Y78 along with four water molecules (Fig. 1C). The structure also led to a hypothesis regarding the high specificity for $\mathrm{K}^{+}$binding over $\mathrm{Na}^{+}$; the oxygen cages were suggested to be unable to properly coordinate smaller ions binding at the same location because the carbonyls would be too far to adequately mimic hydration of $\mathrm{Na}^{+}$. Structural studies of KcsA and $\mathrm{NaK}$ (a channel that conducts both $\mathrm{K}^{+}$and $\mathrm{Na}^{+}$) crystallized in the presence of $\mathrm{Na}^{+}$(and $\mathrm{Li}^{+}$) suggest that instead of binding in the center of the eight-oxygen cage, $\mathrm{Na}^{+}$binds in a plane formed by four oxygens, in between two $\mathrm{K}^{+}$binding sites (Fig. 1C) (Alam and Jiang 2009b; Thompson et al. 2009; Cheng et al. 2011). Therefore, $\mathrm{K}^{+}$channels preferentially pass $\mathrm{K}^{+}$over $\mathrm{Na}^{+}$because either binding is energetically unfavorable or because it encounters a very high-energy barrier to permeate through the pore (Noskov et al. 2004; Zhou and MacKinnon 2004; Lockless et al. 2007; Alam and Jiang 2009b; Thompson et al. 2009; Liu et al. 2012). With these architectural details from the crystal structure of KcsA, the early predictions about the nature of the potassium channel selectivity filter were confirmed to be impressively accurate. In particular, the hypotheses that oxygen cages would be required to coordinate $\mathrm{K}^{+}$ions and that multi-ion occupancy of the selectivity filter would allow for high rate of flux were revealed by the structure to be correct (Bezanilla and Armstrong 1972; Hille and Schwarz 1978; Neyton and Miller 1988a,b). 
In addition to revealing the fundamental principles of selectivity, structural studies with KcsA and other prokaryotic $\mathrm{K}^{+}$channels also proved to be crucial to understanding the regulation of ion flux in potassium channels. Conductance in potassium channels is regulated by two mechanisms, activation gating, and inactivation gating. In general, activation gating is the opening or closing of the channel in response to stimuli, whereas inactivation gating is a cessation of conduction through a channel in the continued presence of the stimulus that activated the channel. These two regulation mechanisms are elegantly coupled to one another to control conductance in potassium channels. In the next section, we will discuss the gating mechanisms used by potassium channels.

\section{GATING}

\section{Activation Gating at the Bundle Crossing}

The KcsA channel structure contains an intracellular gate that separates the cytoplasm from a water-filled cavity just below site S4 (Fig. 1B) (Doyle et al. 1998; Zhou et al. 2001b). This gate is formed by the carboxy-terminal ends of the four TM2 helices gathering together into a so-called bundle crossing to constrict access to the pore. In KcsA, this gate appears to be sterically closed to $\mathrm{K}^{+}$and is stabilized by a complex hydrogen bond network between multiple ionizable residues on each subunit. The binding of protons to some of these residues disrupts the hydrogen bonds and induces electrostatic forces that favor opening the bundlecrossing gate. KcsA is, therefore, found to open at low $\mathrm{pH}$ (high proton concentration) and is completely closed at neutral pH (Doyle et al. 1998; Heginbotham et al. 1999; Cortes et al. 2001; Zhou et al. 2001b; Takeuchi et al. 2007; Thompson et al. 2008).

The second $\mathrm{K}^{+}$channel structure determined by X-ray crystallography was the MthK channel, a $\mathrm{Ca}^{2+}$-activated $\mathrm{K}^{+}$channel from the archaeon Methanothermobacterium thermoautotrophicum (Jiang et al. 2002). MthK is homologous to KcsA, with two transmembrane segments per subunit, but is activated by binding of intracellular $\mathrm{Ca}^{2+}$ to a separate intracellular domain that has been conserved in higher organisms. Because the structure of MthK was solved in the presence of activating $\mathrm{Ca}^{2+}$, it might be expected that the channel would be in an open state. Indeed, in contrast to the closed bundlecrossing gate observed in the KcsA structure, the TM2 helices of MthK are splayed open, without any physical barrier between the intracellular solution and the pore. With these two static pictures, gating can be inferred as a swinging motion at a conserved glycine hinge on the TM2 helix, creating a pivot point to snap the gate shut (open pore conformation of $\mathrm{K}^{+}$channel) (Fig. 2A) (Jiang et al. 2002). Additional crystal structures of prokaryotic and eukaryotic potassium channels support this hypothesis and provide further details about the mechanism (Jiang et al. 2003a; Long et al. 2005, 2007; Alam and Jiang 2009a; Cuello et al. 2010).

Voltage-gated potassium channels are believed to use a bundle-crossing gate analogous to that observed in the KcsA channel (Liu et al. 1997; del Camino and Yellen 2001). The activation gate in many of the eukaryotic Kv channels does not appear to be controlled by a glycine hinge, as in KcsA, but instead appears to result from a hinge formed by the highly conserved amino acid sequence $\mathrm{PxP}$ or $\mathrm{PxG}$, in which $\mathrm{x}$ is typically a hydrophobic residue (Long et al. $2005,2007)$. This region is thought to produce a kink in the gating helix, allowing it to bend or rotate to accommodate the open and closed conformations of the channel, which appears to make a smaller channel opening compared with that observed in the open MthK structure (Doyle et al. 1998; Holmgren et al. 1998; del Camino et al. 2000, 2001; Zhou et al. 2001b; Jiang et al. 2002, 2003a; Long et al. 2005, 2007).

\section{Inactivation Gating: C-Type Inactivation}

Inactivation gating can also occur by a mechanism intrinsic to the pore, known as C-type inactivation (also called slow inactivation) (Kurata and Fedida 2006; McCoy and Nimigean 2012). Here, it is hypothesized that the selectivity filter acts as a gate by closing off conductance even in the presence of ongoing stimulus (Fig. 
D.M. Kim and C.M. Nimigean

A Bundle-crossing gating

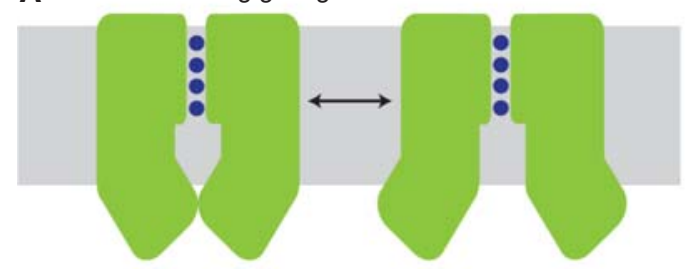

B C-type inactivation and selectivity filter gating

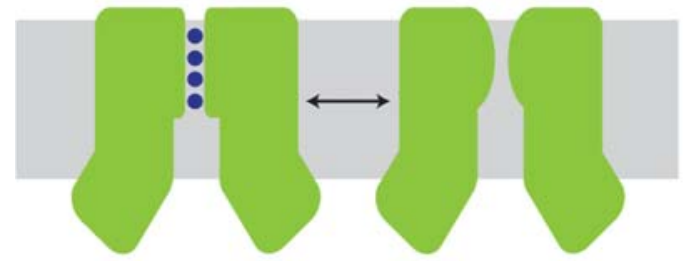

C N-type inactivation

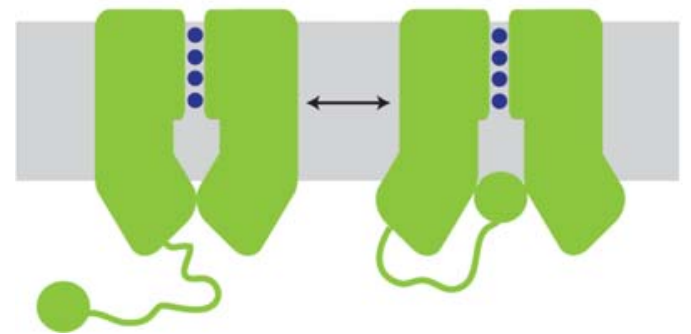

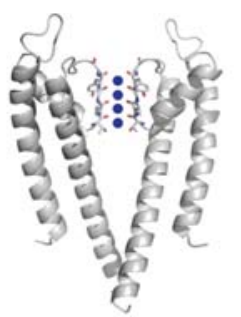
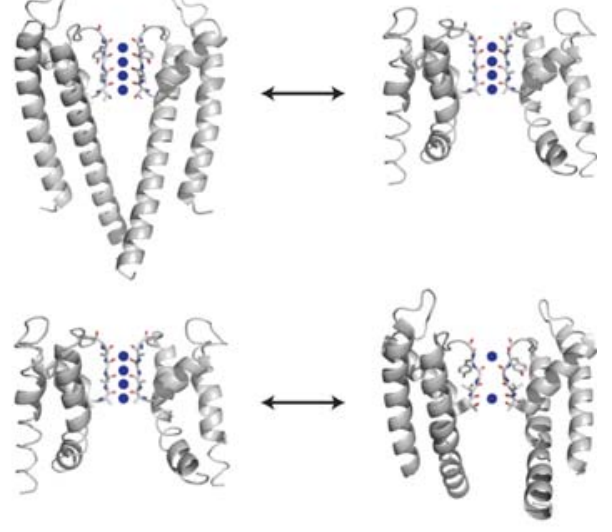

Figure 2. Gating mechanisms of potassium channels. (A) Gating can occur via conformational changes at the bundle crossing. The inner helices physically block the entry of potassium ions into the aqueous cavity, as shown in the KcsA closed structure (left structure, 1K4C). On activation, the inner helices splay open as observed in MthK (right structure, 1LNQ) and expose the cavity. Blue spheres denote potassium ions. (B) C-type inactivation and selectivity filter gating. In this model, partial collapse of the filter prevents conduction of potassium ions through the pore even if the bundle-crossing gate is open. This model is based on the comparison of the open MthK structure (left structure, 1LNQ) to the collapsed filter of a mutant KcsA in the open state (right structure, 3F5W). (C) N-type inactivation, or ball-and-chain gating, results from binding of an autoinhibitory peptide to the bundle-crossing gate to physically block entry of ions into the cavity. This peptide can be part of the amino terminus of the channel (as shown) or the amino terminus of an associated $\beta$ subunit. Currently, no crystal structures exist to illustrate N-type inactivation. The left panels show a cartoon representation of the gating mechanism, and the right panels show the available crystal structures that represent these conformational states.

2B). In addition, C-type inactivation is thought to provide a physiological response to high levels of extracellular $\mathrm{K}^{+}$(Pardo et al. 1992; Baukrowitz and Yellen 1995); thus, it is probably responsible for regulation of repetitive or prolonged electrical activity.

C-type inactivation is believed to be the result of a conformational change in the selectivity filter. Structural studies of KcsA in low potassium concentrations reveal a collapsed selectivity filter (Zhou et al. 2001b), which was hypothesized to represent the inactivated state. Additionally, functional studies identified E71, located behind the selectivity filter, to be an important residue for the inactivation of $\mathrm{KcsA}$, as the E71A mutant completely removed inactivation gating. The KcsA crystal structure shows that this residue interacts with an aspartate and tryptophan as well as with the GYG sequence from the selectivity filter. Mutation of E71 to an alanine results in disruption of these bonds and a conformational change in this aspartate that disrupts the selectivity filter (Cordero-Morales et al. 2006), preventing entry 
Voltage-Gated Potassium Channels

into the collapsed inactivated state even in the absence of $\mathrm{K}^{+}$(Cheng et al. 2011). E71 is not conserved in mammalian $\mathrm{Kv}$ channels and, therefore, the mechanism for C-type inactivation in these channels may be different from that of KcsA. However, mutation of equivalent residues in $\mathrm{Kv}$ channels also produces a disruption of inactivation (Cordero-Morales et al. 2011), suggesting that the conformational dynamics of the selectivity filter are conserved throughout the $\mathrm{K}^{+}$channel superfamily. In addition, studies with Shaker channels show that residues W434 (Perozo et al. 1993; Yang et al. 1997) and Y445 (Hoshi and Armstrong 2013; Armstrong and Hoshi 2014), along with D447 (Molina et al. 1997) and V449 (Lopez-Barneo et al. 1993), play a critical role in C-type inactivation. Nevertheless, other studies show that interfering with collapse of the selectivity filter does not abolish C-type inactivation (Devaraneni et al. 2013) and that water molecules lodged behind the selectivity filter may contribute to the kinetics of inactivation (Ostmeyer et al. 2013); thus, the mechanism of C-type inactivation remains elusive.

\section{Inactivation Gating: N-Type Inactivation}

Another way to regulate conductance through the pore is via N-type inactivation, or the balland-chain mechanism (also called fast inactivation) (Fig. 2C). This mechanism, similar to the bundle-crossing gating, is based on a physical obstruction to $\mathrm{K}^{+}$flux at the intracellular pore entrance. N-type inactivation, however, involves the binding of an autoinhibitory peptide that is either part of the channel (Hoshi et al. 1990) or part of an associated $\beta$ subunit (Rettig et al. 1994) to the open pore. Interestingly, this type of inactivation can be abolished by the simple removal of the amino-terminal peptide (Hoshi et al. 1990), and the phenotype can then be rescued by addition of a soluble peptide of the same sequence (Zagotta et al. 1990). This mechanism is distinct from C-type inactivation, which persists in Shaker channels on deletion of the amino-terminal peptide (Hoshi et al. 1991). Mutational analysis provides evidence that the peptide binds at the cavity site (Zhou et al. 2001a). This mechanism of inactivation is found in several voltage-gated potassium channels. For example, the Shaker channel contains an amino-terminal region that is purported to bind directly to the cavity to block conductance (Demo and Yellen 1991). No direct crystallographic evidence of this mechanism is available to date, but a plausible model was proposed by MacKinnon and coworkers (Long et al. 2005).

\section{Activation Gating at the Selectivity Filter}

Several $\mathrm{K}^{+}$channels, such as the $\mathrm{Ca}^{2+}$-activated $\mathrm{K}^{+}$channels (BK, IK, SK) have been proposed to gate at the selectivity filter (Bruening-Wright et al. 2002; Wilkens and Aldrich 2006; Klein et al. 2007; Tang et al. 2009; Zhou et al. 2011; Thompson and Begenisich 2012) instead of the bundle crossing, unlike KcsA and the voltagegated $\mathrm{K}^{+}$channels mentioned above (Fig. 2B). Removal of the stimulus- $\mathrm{Ca}^{2+}$ in this casepresumably gates $\mathrm{Ca}^{2+}$-activated $\mathrm{K}^{+}$channels by pinching the selectivity filter shut via a conformational change similar to that occurring during C-type inactivation. A constriction at the bundle crossing, insufficient for blocking $\mathrm{K}^{+}$flux through the channel, has been proposed to accompany the selectivity filter closing in BK channels, which are both $\mathrm{Ca}^{2+}$ and voltage-activated (Marty 1981; Latorre and Miller 1983, 1989). Because of complexities in the gating of BK channels, the location of the gate is still uncertain. However, reinforcement in support of the BK-gating mechanism comes from MthK, a prokaryotic homolog of BK channels (Jiang et al. 2003a; Posson et al. 2013), which is gated solely by $\mathrm{Ca}^{2+}$. In functional studies (blocker accessibility with single-channel recording and stopped flow fluorescence assays), MthK was found to gate at the selectivity filter with concomitant movement of intracellular helices (Posson et al. 2013, 2015), lending support to this type of gating mechanism. Conversely, a recent cryo-electron microscopy (cryo-EM) structure of slo2.2, a Na${ }^{+}$-activated $\mathrm{K}^{+}$channel that is a member of the slo family of channels that contain RCK domains, displays a bundle-crossing gate that is sterically closed, which supports the bundle-crossing gate model (Hite et al. 2015). 
D.M. Kim and C.M. Nimigean

These gating mechanisms at the bundle crossing and the selectivity filter serve to modulate conductance in response to environmental stimuli. Therefore, the channels must be able to sense this stimulus and allosterically couple it to a change in gating. Voltage-gated $\mathrm{K}^{+}$channels sense changes in the transmembrane voltage and open or close in response. In the next section, we will explore how voltage-gated $\mathrm{K}^{+}$channels sense shifts in voltage across the cell membrane and how this is coupled to channel gating.

\section{VOLTAGE SENSING IN K ${ }^{+}$CHANNELS}

Voltage-gated ion channels have evolved to provide feedback loops to enhance or diminish electrical activity following a deviation from the resting potential in excitable cells. For example, initial changes in membrane potential occur as a result of opening of voltage-gated $\mathrm{Na}^{+}$ or $\mathrm{Ca}^{2+}$ channels to allow cation influx, resulting in cell depolarization. This depolarization opens more $\mathrm{Na}^{+}$channels, allowing more $\mathrm{Na}^{+}$ influx, which leads to more depolarization. This positive feedback loop leads to the rapid and massive membrane depolarization during the rising phase of the action potential, giving it its "all-or-none" character. Depolarization also opens voltage-gated $\mathrm{K}^{+}$channels, allowing $\mathrm{K}^{+}$ efflux, which, together with rapid $\mathrm{Na}^{+}$channel inactivation, quickly repolarizes the membrane during the falling phase of the action potential. This enables the cell to propagate electrical signals quickly and with high efficiency. The sensitivity of these channels to changes in voltage led early researchers to hypothesize that activation of this conductance must be the result of the movement of charged particles across the membrane electrical field (Hodgkin and Huxley 1952f). Today, we know these "gating charges" are positively charged amino acids on the voltage-sensor domain of voltage-gated channels (Fig. 3A), and that movement of $12-14 \mathrm{e}_{\mathrm{o}}$ gating charges (where $e_{o}$ is the charge of an electron) move across the membrane electric field during gating of the Shaker $\mathrm{Kv}$ channel (Schoppa et al. 1992; Aggarwal and MacKinnon 1996; Seoh et al. 1996). Extensive electrophysiological and structural studies have examined the voltage sensor of Kv channels and shed light on the mechanistic details of how these channels couple voltage sensing to gating.

Before the elucidation of Kv channel crystal structures, many of the fundamental principles about voltage gating were established. Kv channels, like KcsA, are tetrameric but contain six transmembrane helices S1-S6 (Fig. 3A). Helices $\mathrm{S} 1-\mathrm{S} 4$ were found to form the voltage sensors, whereas S5-S6, homologous to TM1 and TM2 in KcsA and MthK, form the pore (Tempel et al. 1987; Kamb et al. 1988; Pongs et al. 1988; MacKinnon 1991). The prediction that the voltage-sensor region would contain multiple positively charged residues (Hodgkin and Huxley 1952f ) enabled the identification of this region by sequence analysis (Noda et al. 1984). One region was found to be highly conserved among all voltage-gated ion channels $\left(\mathrm{Na}^{+}, \mathrm{Ca}^{2+}\right.$, and $\mathrm{K}^{+}$channels) in the fourth transmembrane helix, S4 (Noda et al. 1984). This sequence motif contains an arginine or lysine at every third position, and mutagenesis studies have largely supported the hypothesis that these residues comprise the gating charges that move across the membrane to gate the channels (Aggarwal and MacKinnon 1996; Seoh et al. 1996). Indeed, the movement of these gating charges can be measured as transient electrical currents that are distinct from ion conduction (Armstrong and Bezanilla 1973; Schneider and Chandler 1973; Keynes and Rojas 1974). Voltage-dependent translocation of these charges was confirmed by cysteine-scanning mutagenesis and subsequent testing for voltage-dependent accessibility of cysteine-modifying agents (Larsson et al. 1996; Yang et al. 1996). Studies using fluorescently labeled channels also support conformational changes in S4 during gating (Mannuzzu et al. 1996; Cha and Bezanilla 1997; Bezanilla 2000). Collectively, these studies provided a model in which the $S 4$ helices moved within the transmembrane region in response to changes in voltage. Most of these functional predictions were confirmed with the elucidation of the crystal structures of $\mathrm{Kv}$ channels at atomic resolution.

Several voltage-gated $\mathrm{K}^{+}$channel structures have been solved to date: KvAP from the ther- 

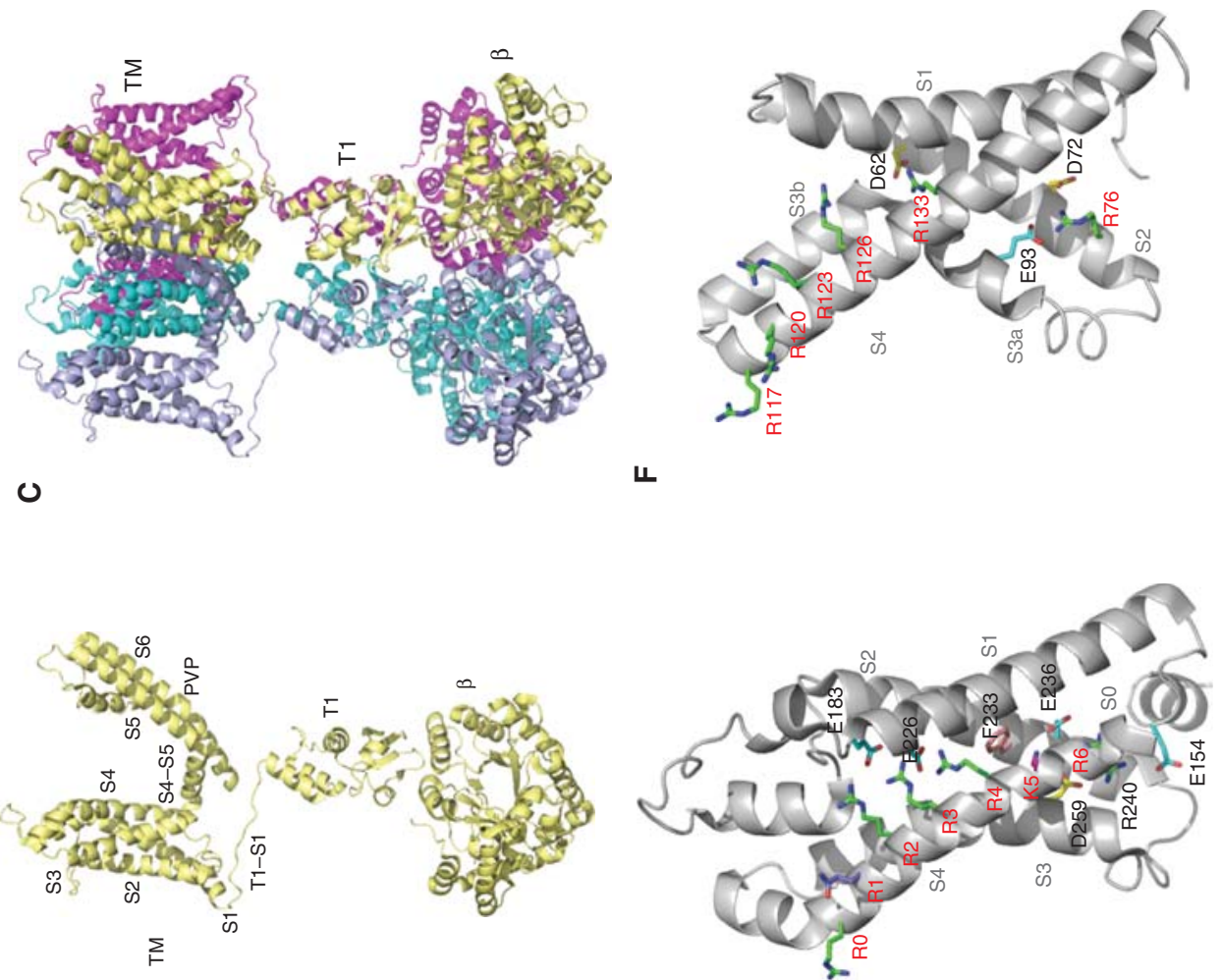

ш

$\mathbf{m}$

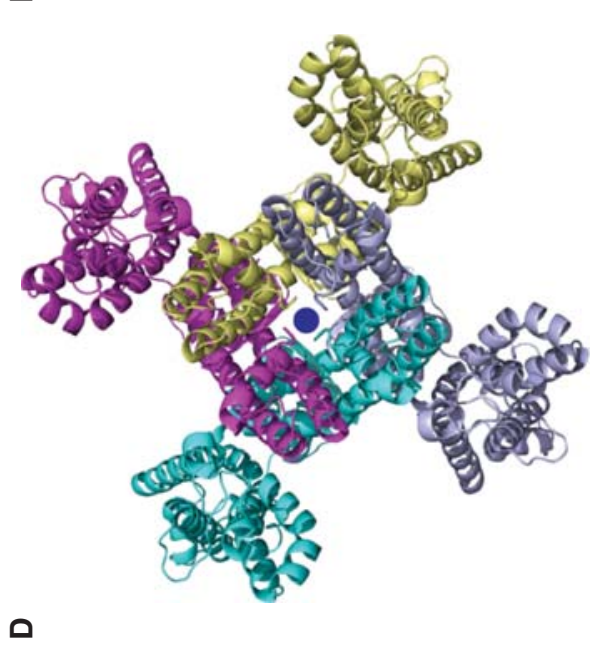

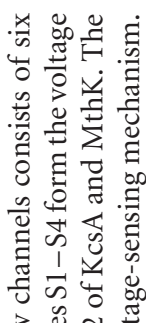

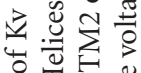

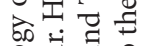

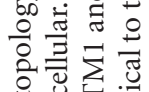

芶。苛

켁.छ

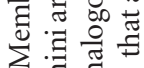

ชิ चี

元

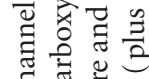

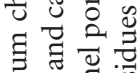

.

寻艺

푤

馬

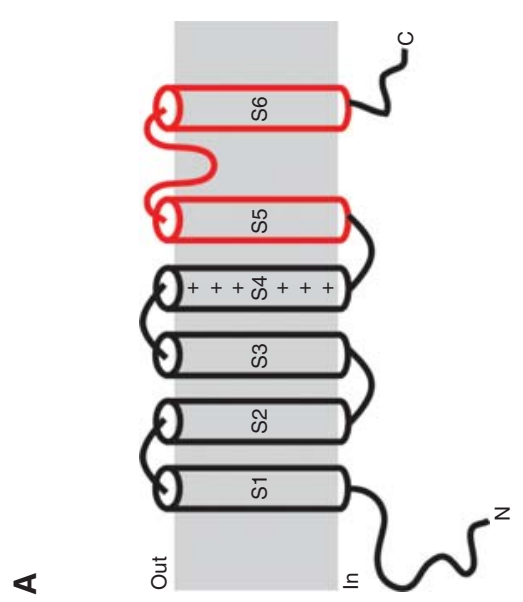

ปี

चै छे हैं

㐫

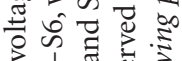

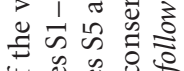

प. \&

寻寻

记 卷.志

㫄泀过

ข

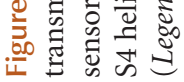


D.M. Kim and C.M. Nimigean

mophilic archaebacteria Aeropyrum pernix at $3.2 \AA$ (Jiang et al. 2003a), Kv1.2 channel from rat (Long et al. 2005) to $2.9 \AA$, and a chimeric Kv1.2 channel containing a section of the voltage sensor from Kv2.1 (called the S3b-S4 voltage-sensor paddle) (Long et al. 2007) at $2.4 \AA$. These structures share certain features, including the $\mathrm{K}^{+}$channel selectivity filter, which is identical to that of KcsA, and the overall architecture of the pore. The pore is in an apparent open conformation because of the similarity of the bundle crossing to the open MthK structure rather than to the constricted KcsA structure (Fig. 3B-D, compare with Fig. 2, right panels). The voltage-sensor domains of the Kv1.2 and chimera Kv1.2/2.1 are very similar and are also similar to the isolated voltage sensor of KvAP (Fig. 3E,F). However, because the KvAP was crystallized in the absence of lipids and with a bound antibody fragment, its voltage sensor appears to be in a distorted conformation compared with $\mathrm{Kv}$ channels crystallized with lipids (Jiang et al. 2003a; Lee et al. 2005; Long et al. 2005, 2007). Our discussion will include the structural features of KvAP, Kv1.2, and the chimeric eukaryotic Kv1.2/2.1, but we will mainly refer to the structure of the chimera (shown in Fig. 3B-E) because of its high resolution.

\section{The Structure of the Voltage Sensor in Voltage-Gated $\mathrm{K}^{+}$Channels}

Structural studies of KvAP, Kv1.2, and Kv1.2/2.1 chimera show that the voltage-sensor domain $(\mathrm{S} 1-\mathrm{S} 4)$ is conserved between eukaryotes and prokaryotes (Fig. 3E,F). S3 and S4 adopt an antiparallel arrangement forming a paddle that may move as a unit, and the voltage sensors are in a conformation that exposes the gating charges to the extracellular solution, providing further support for the channel being in the activated open state. The voltage sensors are unexpectedly located on the outside of the channel pore and are not tightly packed against the pore (Fig. 3D). This arrangement led to the hypothesis that the voltage sensors are independent and that the shielding of gating charges from the lipid as well as interactions with countercharges may occur within the voltage-sensing domain itself (Papazian et al. 1987; Long et al. 2007).

The high resolution of the voltage-sensor domain allows for detailed mapping of previous functional data onto the structure (Fig. 3E). The structure clearly shows the interactions between the conserved gating charge residues R1-R4 with their acidic countercharges on helices S0-S3a. The arginine residues make contacts with conserved Glu and Asp residues in two regions, at the intracellular and extracellular sides, separated by $15 \AA$ and by a hydrophobic patch at F233 on helix S2 (Fig. 3E). This Phe residue is a highly conserved residue in $\mathrm{Kv}$ channels and is located near the midpoint of the membrane, but is absent in the KvAP voltagesensing domain (Fig. 3F). In addition, the structure also shows a 310 -helix hydrogen-bonding pattern in the lower half of the S4 helix, which elongates S4 by $5 \AA$ compared with an $\alpha$-helix, thus bringing it closer to the extracellular side

Figure 3. (Continued) (B) The crystal structure of a chimeric channel comprised of the Kv1.2 with the voltagesensor paddle of Kv2.1, crystallized in the presence of detergent and lipids (PDBID:2R9R). The $\beta$ subunit is bound to the channel via the T1 intracellular domain. One subunit is depicted here and helices $\mathrm{S} 1-\mathrm{S} 6$, the $\mathrm{S} 4-\mathrm{S} 5$ linker, the PVP hinge, and the T1-S1 linker are indicated. (C) Side view of the channel tetramer $\beta$ subunit complex. (D) Top view of the channel tetramer. Each subunit is differently colored, and the channel pore is visible in the center of the structure. The voltage-sensing domains are located outside of the channel pore. A potassium ion is shown as a blue sphere. (E) A detailed view of the voltage-sensor domain of the chimeric channel. Critical arginine residues are shown as green sticks and labeled as the putative gating charges R0-R4, followed by $\mathrm{K} 5$ and R6 on the S4 helix. Two clusters of negatively charged residues serve as countercharges to the gating charges on the external side (E183 and E226) and the internal side (E154, E236, and D259) and are separated by the F233 on S2. (F) The 1.9 $\AA$ resolution structure of the isolated voltage-sensor domain of KvAP (PDBID:1ORQ). Critical arginine residues on the S4 helix are shown in green sticks. Gating charge R133 forms a salt bridge with D62 on the S2 helix, whereas R76, D72, and E93 form a salt-bridge network to bridge S2 with S3a. 
and also directing the Arg and Lys residues at every third position to occupy the same face of the helix (Long et al. 2007).

This presumed open state structure shows that the first five arginines on the S4 helix (R0R4) are close to the extracellular side and reside in an aqueous cleft (Fig 3E). The structure is consistent with the $12-14 \mathrm{e}_{\mathrm{o}}$ gating charges per channel previously calculated for Shaker (Schoppa et al. 1992; Aggarwal and MacKinnon 1996; Seoh et al. 1996), with R1-R4 each contributing a gating charge. Movement of R1-R4 toward the intracellular side would result in closing of the channel, as evidenced by cysteine accessibility experiments (Larsson et al. 1996), requiring a large translation of S4 toward the internal solution. Further support for this mechanism was provided by avidin-biotin accessibility studies on KvAP, which suggested that a $15 \AA$ downward movement of S4 is required for closing (Ruta et al. 2005). However, other studies suggest that movement of the gating charges requires a smaller translation of S4 (Starace and Bezanilla 2001, 2004; Posson et al. 2005). The structural and functional data on $\mathrm{Kv}$ channels provide the starting point for understanding the molecular mechanism for how the S4 helix may move downward, as much as $\sim 15 \AA$, in the presence of a negative membrane voltage to close the channel. To date, we have no crystal structure of a closed Kv channel, with gating charges in contact with the intracellular solution. However, models of the resting state have emerged from both experimentally and computationally derived evidence (Yarov-Yarovoy et al. 2006, 2012; Campos et al. 2007; Pathak et al. 2007; DeCaen et al. 2008, 2009, 2011; Delemotte et al. 2010; Henrion et al. 2012; Jensen et al. 2012; Vargas et al. 2012), and advances have been made in obtaining closed state structures of the VSD alone ( $\mathrm{Li}$ et al. 2014a,b) as discussed below.

\section{Coupling between the Voltage Sensor and the Channel Gate}

These structural studies suggest a hypothesis for how ion channel gating is coupled to the voltage-sensing mechanism (Fig. 4) (Long et al.
2007). The investigators propose that coupling is made possible by the PVP hinge region in eukaryotes (glycine in prokaryotes), which produces curvature in the S6 inner helix. This allows for the S4-S5 linker to cross over the top of the $\mathrm{S} 6$ inner helix. A large inward displacement of the $\$ 4$ voltage sensor would push down on the S4-S5 linker, ultimately causing the S6 helix to constrict the pore and close the channel (Fig. $4 \mathrm{~B})$. Therefore, the interaction between the S4S5 linker and the S6 helix appears to be crucial to coupling of the movements in the voltage sensor to gating. The critical arginine residues were proposed to move between two clusters of countercharges, separated by $\sim 15 \AA$, which are strategically placed on S0-S3 during gating. This mechanism is likened to a switch transition, requiring the arginines to cross a hydrophobic patch at F233 to close the channel. With these mechanistic details, the chimeric channel structure along with the KvAP and Kv1.2 structures could provide an emerging model to correlate functional data with the structural properties of a Kv channel.

\section{Voltage-Sensor Movement between Up and Down Conformations}

The observation that the voltage sensor is in a sense "floating" as a separate domain from the pore in the structure suggests that these domains can move independently of the remainder of the channel. Gating is retained when the voltage sensor is separated from the pore by cutting the S4-S5 linker in the KCNH family of $\mathrm{Kv}$ channels (Lorinczi et al. 2015). However, this is in direct contradiction to the putative role of the linker in the coupling mechanism suggested by the chimera structure (Long et al. 2007). KCNH channels lack the PVP motif, and, therefore, the coupling mechanism may differ in this channel family. The independent nature of the voltage-sensing domain allows its functional transfer to a nonvoltage dependent $\mathrm{K}^{+}$channel (Lu et al. 2001) or from one channel to another (Alabi et al. 2007). In addition, this explains the ability to express the voltage-sensing domain in the absence of an associated channel pore (Jiang et al. 2003b). Furthermore, 
D.M. Kim and C.M. Nimigean

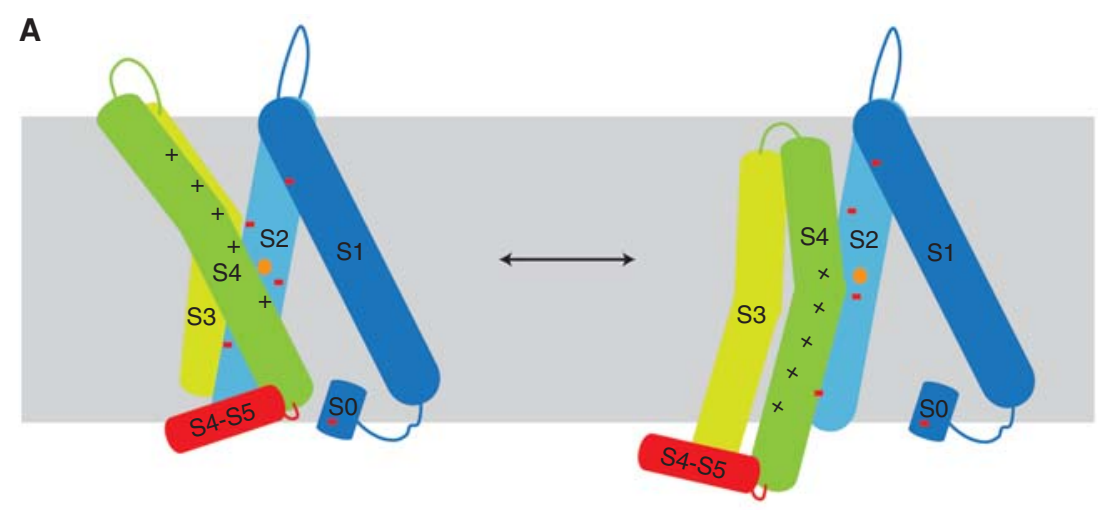

B

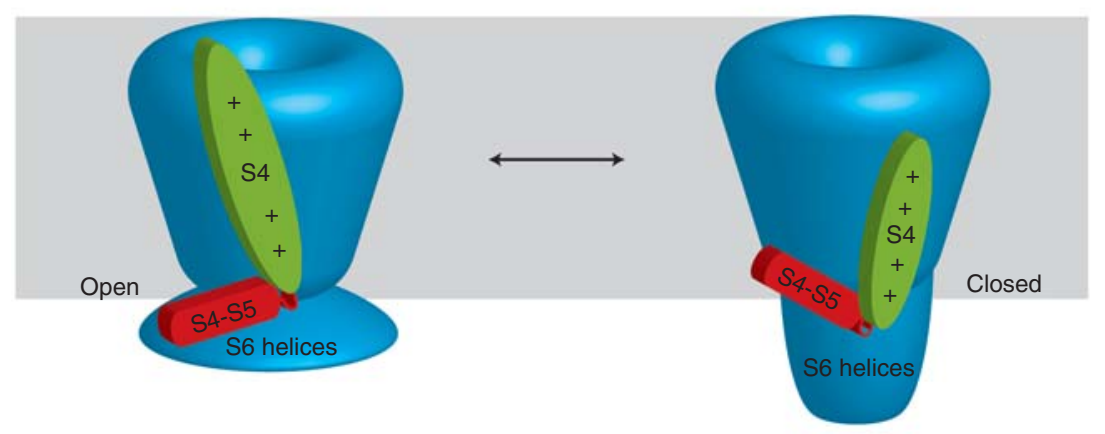

C

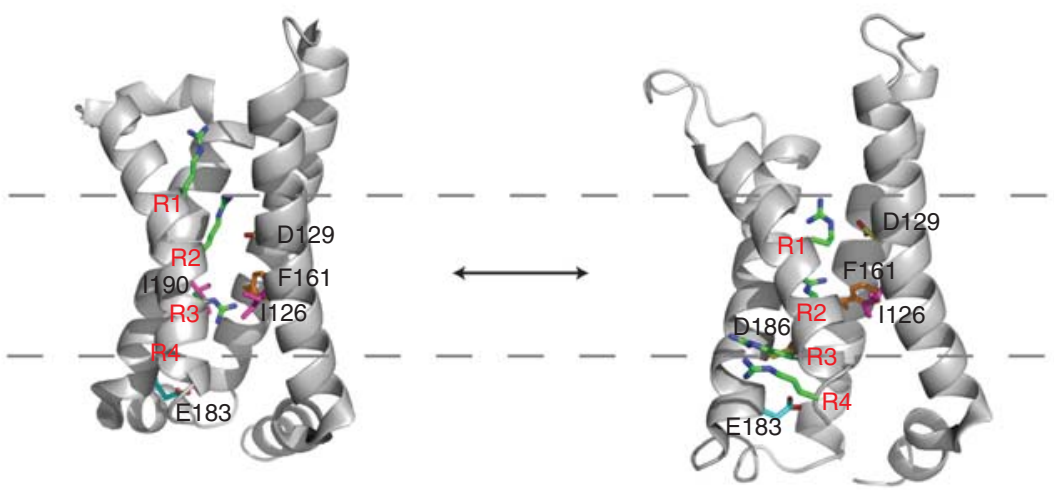

Figure 4. A model for coupling of voltage sensing to channel opening in Kv channels. (A) A cartoon depiction of the paddle model (Long et al. 2007) voltage-sensing mechanism. Helices S1-S4 and the S4-S5 linker are shown as cylinders of different colors. Gating charges are located on the S4 helix and represented by a black + sign. Countercharges on S0 (a short $\alpha$-helical region before S1), S1, and S2 are represented by a red dash. In the up or open conformation (left), S3 and S4 are located within the membrane and the gating charges are closer to the extracellular side, interacting with the external cluster of countercharges. The hydrophobic plug is represented by an orange circle on the S2 helix. A change in membrane potential would cause the S4 helix to move into the down conformation (right) with the gating charges now closer to the intracellular side and interacting with the internal cluster of countercharges. This displacement of S4 pushes down on the S4-S5 linker, tilting it toward the intracellular side, poising it to interact with the $S 6$ helices to close the pore. $(B)$ The proposed mechanism for coupling of voltage sensing to gating in $\mathrm{Kv}$ channels (Long et al. 2007). The channel pore and bundle crossing are represented in blue. S4 and the S4-S5 helix of the voltage-sensing domain are depicted in green and red, respectively. (Legend continues on following page.) 
Hv1 proton channels lack a canonical pore domain but retain a voltage-gating mechanism (Ramsey et al. 2006; Sasaki et al. 2006; Lee et al. 2009), providing further support for the independent nature of the voltage-sensing domain. Finally, this feature also enables voltagesensing capabilities in nonchannel proteins, such as the voltage-dependent phosphatase enzyme, which contains the S1-S4 helices but does not contain a pore or function as a channel (Murata et al. 2005; Kohout et al. 2008). Therefore, the voltage-sensing domain has evolved to couple voltage-dependent conformational changes to a variety of physiological processes. Studies of both chimeric channels and the voltage-sensing phosphatases have provided considerable advancements in understanding the detailed mechanism of voltage-dependent conformational changes in $\mathrm{Kv}$ channels.

Because all the reported Kv crystal structures were in the open state, one obvious missing piece of this puzzle was a high-resolution structure of a Kv channel in the closed state to verify this mechanism and further expand the model. Recent studies of the lipid-dependence of KvAP and voltage-dependent phosphatases have filled in this gap (Li et al. 2014a,b). The difficulty in capturing the closed state of a Kv channel may be because this conformation requires an electric field with negative voltage, and the crystallization process occurs at $0 \mathrm{mV}$. All crystal structures may, thus, be in the activated/inactivated state with the voltage sensors in the up conformation. Therefore, it is necessary to bias toward the closed conformation using other methods. Previous experiments with voltage-gated channels showed that lipid-protein interactions could change the energetic landscape of membrane-reconstituted $\mathrm{Kv}$ channels, suggesting that transitions between the up and down conformations could require gating-charge interactions with surrounding phospholipids (Ramu et al. 2006; Schmidt et al. 2006; Xu et al. 2008; Zheng et al. 2011). In the absence of phospholipids, voltage sensors are "trapped" in the down conformation (Zheng et al. 2011). This was exploited in studies of the KvAP voltage-sensing domain, which used site-directed spin labeling and EPR to show that non-phosphate-containing lipids could trigger the reorientation of the S4 helix, producing a sensor in the down state at $0 \mathrm{mV}$ (Li et al. 2014b). This study showed that in DOTAP lipids, $\mathrm{S} 4$ is displaced downward by only $2 \AA$ (compared with the $15 \AA$ predicted by Long et al. 2007) and also tilts away from S1 and S2 by $3 \AA$ A. This suggests a new "tilt-shift" model, which is supported by previous studies (Posson et al. 2005) and joins the sliding helix-helical screw model (Catterall 1986; Guy and Seetharamulu 1986), the tethered hydrophobic cation sensor (Jiang et al. 2003a,b; Ruta et al. 2005), and refocusing of the electric field around gating charges (Yang et al. 1996; Chanda and Bezanilla 2008) as possible models for voltage sensing. The KvAP study with DOTAP lipids shows that the down state of the sensor, either a closed state or an intermediate state not fully closed, can be analyzed in the absence of an electric field by biasing the conformational equilibrium in a lipid-dependent manner.

The crystal structure of a voltage-sensing domain in the down state was elucidated using a similar approach to bias the domain toward one state. The discovery of voltage-sensing

Figure 4. (Continued) Based on the crystal structure, S4 is in the up conformation (left), and the S4-S5 linker rests on the S6 helices in the bundle crossing in the open state. Transition to the hypothetical closed state of the channel requires movement of S4 into the down conformation (right). This downward movement of the S4 helix pushes on the amino-terminal end of the S4-S5 helix, which tilts toward the intracellular side and pushes the S6 helices down into the closed state. $(C)$ A comparison of the conformational states of the voltage-sensing phosphatase Ci-VSP. R217E Ci-VSP (left, PDBID:4G7V) shows the voltage sensor in the up conformation, whereas wild-type Ci-VSP (right, PDBID:4G80) shows the voltage sensor in the down conformation. The structures were aligned using the S1 helix for reference. Critical Arg residues R1-R4 are shown as green sticks. Countercharges are shown along with residues comprising the hydrophobic plug region. The gray dotted lines denote the position of R1 (top) and R4 (bottom) on the up conformation of R217E Ci-VSP for comparison to their positions on the down conformation of wild-type. 
D.M. Kim and C.M. Nimigean

phosphatases (VSPs) revealed that voltage-sensing domains are not limited to ion channels (Murata et al. 2005). The VSP from Ciona intenstinalis (Ci-VSP) contains a PTEN-related phosphoinositide phosphatase (Matsuda et al. 2011), which is under the control of a canonical voltage-sensing domain that has high sequence similarity to $\mathrm{S} 1-\mathrm{S} 4$ of $\mathrm{Kv}$ channels ( $\mathrm{Li}$ et al. 2014a). These enzymes have a Q-V curve that is shifted to more positive potentials with halfmaximal voltage near $+60 \mathrm{mV}$ (Murata et al. 2005); therefore, at $0 \mathrm{mV}$, the VSP should be in the down conformation. In addition, a mutation was identified, which results in a negative shift of $120 \mathrm{mV}$ with a half-maximal voltage near $-60 \mathrm{mV}$ (Villalba-Galea et al. 2008; Li et al. 2014a), providing a simple strategy to obtain the active or up conformation at $0 \mathrm{mV}$. Therefore, crystal structures could be obtained of the same protein in the active and resting states with little manipulation. The structures show that, in contrast to $\mathrm{Kv}$ channels, there are no countercharges in S2 of Ci-VSP (Fig. 4C) (Li et al. 2014a). However, the hydrophobic patch is conserved and formed by a pair of isoleucines and a phenylalanine (Fig. 4C), similar to $\mathrm{Kv}$ channels, and functions as separating partition between the two sides of the membrane as well as a dielectric barrier to the permeation of water and ions. Alignment of the activated (voltage sensor up) and resting (voltage sensor down) structures shows displacement of the S4 helix by $5 \AA$ downward with every gating charge in a one-click down fashion, along with a $60^{\circ}$ clockwise rotation, differing from the $15 \AA$ movement of S4 in the paddle model but supporting the sliding helix-helical screw model (Fig. 4C). Comparison of these structures to the Kv channel structures (Fig. 3E,F) suggests that there are mechanistic variances in voltage sensing owing to the different positions of the gating charges and also their interactions with the coevolved countercharges. These studies with the voltage-dependent phosphatases, in conjunction with studies of the lipid-dependent conformational states of KvAP (Li et al. 2014a,b), foster a greater understanding of the structural and mechanistic details of the active and resting states.
Molecular Dynamics Simulations of the Voltage-Sensor Movement

To fully understand how voltage sensors work, it is imperative to elucidate the myriad transition states that connect these two conformations. In silico studies using molecular dynamics (MDs) and Rosetta modeling techniques fill this gap by theorizing the conformational states that have not been elucidated by crystallography, using functional data as constraints to model voltage-sensor movement and channel gating. Available MD simulations to date using the known crystal structures as starting points are in agreement with most of the functional data (Jensen et al. 2012; Vargas et al. 2012). These studies tend to dispute the paddle mechanism although providing support for the classical sliding helix-helical screw model. A major caveat of these studies, however, is the requirement to use large hyperpolarizing potentials $(750 \mathrm{mV})$ to allow for the voltage-dependent transition toward the resting state to occur within accessible computing time. The resulting resting state models show the S4 helix to be rotated and translated inward along the main axis relative to the up conformation observed in the crystal structures, whereas the S1 and S2 helices retain their position (Jensen et al. 2012). In the resting state, $\mathrm{R} 1$ is positioned between the countercharges E1 and E2 on the S2 helix, above the Phe residue (Fig. 3E). This positions positive gating charges to form salt bridges with countercharges on S1-S3. Kinetic models of voltage gating in Shaker (Islas and Sigworth 2001; Asamoah et al. 2003; Starace and Bezanilla 2004) are also supported by MD simulations showing that the ion conducting pore closes before any of the VSDs have transitioned to the most stable resting state conformation (Jensen et al. 2012), which is further validated by crystal structures of the bacterial Nav channel (Payandeh et al. 2011, 2012; Zhang et al. 2012). The agreement of these MD studies with structural and functional data provides a sense of validation; however, no experimental data has been obtained at $750 \mathrm{mV}$, and, therefore, dynamic properties of gating could be somewhat skewed in these studies. 


\section{CONCLUSION}

The evolution of a relatively small helical domain that can sense changes in voltage across the cell membrane and relay that information to control gating of potassium channels is a feat of nature. Understanding how the voltagesensing domain can move in response to a change in membrane potential and couple this to conformational changes at the pore is crucial to deciphering the sophisticated mechanisms of gating in Kv channels. Experimental studies with a wide variety of techniques, such as electrophysiology and crystallography, together with in silico MD simulations and computational modeling studies, provide us with an enriched understanding of how these machines work. Although a clearer picture of the mechanistic details of voltage-dependent gating is emerging, many questions linger about these fascinating ion channels.

\section{REFERENCES}

Aggarwal SK, MacKinnon R. 1996. Contribution of the S4 segment to gating charge in the Shaker $\mathrm{K}^{+}$channel. Neuron 16: 1169-1177.

Alabi AA, Bahamonde MI, Jung HJ, Kim JI, Swartz KJ. 2007. Portability of paddle motif function and pharmacology in voltage sensors. Nature 450: $370-375$.

Alam A, Jiang Y. 2009a. High-resolution structure of the open NaK channel. Nat Struct Mol Biol 16: 30-34.

Alam A, Jiang Y. 2009b. Structural analysis of ion selectivity in the NaK channel. Nat Struct Mol Biol 16: 35-41.

Almers W, McCleskey EW. 1984. Non-selective conductance in calcium channels of frog muscle: Calcium selectivity in a single-file pore. J Physiol 353: 585-608.

Armstrong CM, Bezanilla F. 1973. Currents related to movement of the gating particles of the sodium channels. $\mathrm{Na}$ ture 242: $459-461$

Armstrong CM, Hoshi T. 2014. $\mathrm{K}^{+}$channel gating: C-type inactivation is enhanced by calcium or lanthanum outside. J Gen Physiol 144: 221-230.

Asamoah OK, Wuskell JP, Loew LM, Bezanilla F. 2003. A fluorometric approach to local electric field measurements in a voltage-gated ion channel. Neuron 37: $85-97$.

Baukrowitz T, Yellen G. 1995. Modulation of $\mathrm{K}^{+}$current by frequency and external $\left[\mathrm{K}^{+}\right]$: A tale of two inactivation mechanisms. Neuron 15: 951-960.

Begenisich TB, Cahalan MD. 1980. Sodium channel permeation in squid axons. II: Non-independence and currentvoltage relations. J Physiol 307: 243-257.
Bernstein J. 1902. Untersuchungen zur thermodynamik der bioelektrischen Ströme [Studies on thermodynamics of bioelectrical currents]. Pflügers Arch 92: 521-562.

Bezanilla F. 2000. The voltage sensor in voltage-dependent ion channels. Physiol Rev 80: 555-592.

Bezanilla F, Armstrong CM. 1972. Negative conductance caused by entry of sodium and cesium ions into the potassium channels of squid axons. J Gen Physiol 60: 588608.

Bruening-Wright A, Schumacher MA, Adelman JP, Maylie J. 2002. Localization of the activation gate for small conductance $\mathrm{Ca}^{2+}$-activated $\mathrm{K}^{+}$channels. J Neurosci 22: 6499-6506.

Cahalan M, Begenisich T. 1976. Sodium channel selectivity. Dependence on internal permeant ion concentration. J Gen Physiol 68: 111-125.

Campos FV, Chanda B, Roux B, Bezanilla F. 2007. Two atomic constraints unambiguously position the S4 segment relative to S1 and S2 segments in the closed state of Shaker K channel. Proc Natl Acad Sci 104: 7904-7909.

Catterall WA. 1986. Molecular properties of voltage-sensitive sodium channels. Annu Rev Biochem 55: 953-985.

Cha A, Bezanilla F. 1997. Characterizing voltage-dependent conformational changes in the Shaker $\mathrm{K}^{+}$channel with fluorescence. Neuron 19: 1127-1140.

Chanda B, Bezanilla F. 2008. A common pathway for charge transport through voltage-sensing domains. Neuron 57: 345-351.

Chandler WK, Meves H. 1965. Voltage clamp experiments on internally perfused giant axons. J Physiol 180: 788820.

Cheng WW, McCoy JG, Thompson AN, Nichols CG, Nimigean CM. 2011. Mechanism for selectivity-inactivation coupling in KcsA potassium channels. Proc Natl Acad Sci 108: $5272-5277$.

Cordero-Morales JF, Cuello LG, Zhao Y, Jogini V, Cortes DM, Roux B, Perozo E. 2006. Molecular determinants of gating at the potassium-channel selectivity filter. Nat Struct Mol Biol 13: 311-318.

Cordero-Morales JF, Jogini V, Chakrapani S, Perozo E. 2011 A multipoint hydrogen-bond network underlying KcsA C-type inactivation. Biophys J 100: 2387-2393.

Cortes DM, Cuello LG, Perozo E. 2001. Molecular architecture of full-length KcsA: Role of cytoplasmic domains in ion permeation and activation gating. J Gen Physiol 117: $165-180$.

Cuello LG, Jogini V, Cortes DM, Pan AC, Gagnon DG, Dalmas O, Cordero-Morales JF, Chakrapani S, Roux B, Perozo E. 2010. Structural basis for the coupling between activation and inactivation gates in $\mathrm{K}^{+}$channels. Nature 466: $272-275$.

DeCaen PG, Yarov-Yarovoy V, Zhao Y, Scheuer T, Catterall WA. 2008. Disulfide locking a sodium channel voltage sensor reveals ion pair formation during activation. Proc Natl Acad Sci 105: 15142-15147.

DeCaen PG, Yarov-Yarovoy V, Sharp EM, Scheuer T, Catterall WA. 2009. Sequential formation of ion pairs during activation of a sodium channel voltage sensor. Proc Natl Acad Sci 106: 22498-22503.

DeCaen PG, Yarov-Yarovoy V, Scheuer T, Catterall WA. 2011. Gating charge interactions with the S1 segment during 
D.M. Kim and C.M. Nimigean

activation of a Na${ }^{+}$channel voltage sensor. Proc Natl Acad Sci 108: $18825-18830$.

del Camino D, Yellen G. 2001. Tight steric closure at the intracellular activation gate of a voltage-gated $\mathrm{K}^{+}$channel. Neuron 32: 649-656.

del Camino D, Holmgren M, Liu Y, Yellen G. 2000. Blocker protection in the pore of a voltage-gated $\mathrm{K}^{+}$channel and its structural implications. Nature 403: 321-325.

Delemotte L, Treptow W, Klein ML, Tarek M. 2010. Effect of sensor domain mutations on the properties of voltagegated ion channels: Molecular dynamics studies of the potassium channel Kv1.2. Biophys J 99: L72-L74.

Demo SD, Yellen G. 1991. The inactivation gate of the Shaker $\mathrm{K}^{+}$channel behaves like an open-channel blocker. Neuron 7: 743-753.

Devaraneni PK, Komarov AG, Costantino CA, Devereaux JJ, Matulef K, Valiyaveetil FI. 2013. Semisynthetic $\mathrm{K}^{+}$channels show that the constricted conformation of the selectivity filter is not the C-type inactivated state. Proc Natl Acad Sci 110: 15698-15703.

Doyle DA, Morais Cabral J, Pfuetzner RA, Kuo A, Gulbis JM, Cohen SL, Chait BT, MacKinnon R. 1998. The structure of the potassium channel: Molecular basis of $\mathrm{K}^{+}$conduction and selectivity. Science 280: 69-77.

Eisenman W. 1962. A two-way affair. Science 136: 182.

Eisenman G, Latorre R, Miller C. 1986. Multi-ion conduction and selectivity in the high-conductance $\mathrm{Ca}^{2+}$-activated $\mathrm{K}^{+}$channel from skeletal muscle. Biophys $J \mathbf{5 0}$ 1025-1034.

Goldman DE. 1943. Potential, impedance, and rectification in membranes. J Gen Physiol 27: 37-60.

Guy HR, Seetharamulu P. 1986. Molecular model of the action potential sodium channel. Proc Natl Acad Sci 83: 508-512.

Hagiwara S, Takahashi K. 1974. Mechanism of anion permeation through the muscle fibre membrane of an elasmobranch fish, Taeniura lymma. J Physiol 238: 109-127.

Heckmann K. 1965a. Zur theorie der "single file"-diffusion. Part I. Z Phys Chem 44: 184-203.

Heckmann K. 1965b. Zur theorie der "single file"-diffusion. Part II. Z Phys Chem 46: 1-25.

Heckmann K. 1968. Zur theorie der "single file"-diffusion. Part III: Sigmoide Konzantratonsabhangigkeit unidirectionaler flusse bei "single file" diffusion. Z Phys Chem 58: 210-219.

Heckmann K. 1972. Single-file diffusion. Plenum, New York.

Heginbotham L, MacKinnon R. 1993. Conduction properties of the cloned Shaker $\mathrm{K}^{+}$channel. Biophys J 65: 20892096.

Heginbotham L, Abramson T, MacKinnon R. 1992. A functional connection between the pores of distantly related ion channels as revealed by mutant $\mathrm{K}^{+}$channels. Science 258: $1152-1155$.

Heginbotham L, Lu Z, Abramson T, MacKinnon R. 1994. Mutations in the $\mathrm{K}^{+}$channel signature sequence. Biophys J 66: 1061-1067.

Heginbotham L, LeMasurier M, Kolmakova-Partensky L, Miller C. 1999. Single streptomyces lividans $\mathrm{K}^{+}$channels: Functional asymmetries and sidedness of proton activation. J Gen Physiol 114: 551-560.
Henrion U, Zumhagen S, Steinke K, Strutz-Seebohm N, Stallmeyer B, Lang F, Schulze-Bahr E, Seebohm G. 2012. Overlapping cardiac phenotype associated with a familial mutation in the voltage sensor of the KCNQ1 channel. Cell Physiol Biochem 29: 809-818.

Hess P, Tsien RW. 1984. Mechanism of ion permeation through calcium channels. Nature 309: 453-456.

Hille B. 1973. Potassium channels in myelinated nerve. Selective permeability to small cations. J Gen Physiol 61: 669-686.

Hille B. 1975a. Ionic selectivity of $\mathrm{Na}$ and K channels of nerve membranes. Membranes 3: 255-323.

Hille B. 1975b. Ionic selectivity, saturation, and block in sodium channels. A four-barrier model. J Gen Physiol 66: $535-560$.

Hille B. 2001. Ion channels of excitable membranes. Sinauer Associates, Sunderland, MA.

Hille B, Schwarz W. 1978. Potassium channels as multi-ion single-file pores. J Gen Physiol 72: 409-442.

Hite RK, Yuan P, Li Z, Hsuing Y, Walz T, MacKinnon R. 2015. Cryo-electron microscopy structure of the Slo2.2 Na-activated K channel. Nature 527: 198-203.

Hodgkin AL, Huxley AF. 1945. Resting and action potentials in single nerve fibres. J Physiol 104: 176-195.

Hodgkin AL, Huxley AF. 1946. Potassium leakage from an active nerve fibre. Nature 158: 376.

Hodgkin AL, Huxley AF. 1947. Potassium leakage from an active nerve fibre. J Physiol 106: 341-367.

Hodgkin AL, Huxley AF. 1952a. The components of membrane conductance in the giant axon of Loligo. J Physiol 116: $473-496$.

Hodgkin AL, Huxley AF. 1952b. Currents carried by sodium and potassium ions through the membrane of the giant axon of Loligo. J Physiol 116: 449-472.

Hodgkin AL, Huxley AF. 1952c. The dual effect of membrane potential on sodium conductance in the giant axon of Loligo. J Physiol 116: 497-506.

Hodgkin AL, Huxley AF. 1952d. Movement of sodium and potassium ions during nervous activity. Cold Spring Harb Symp Quant Biol 17: 43-52.

Hodgkin AL, Huxley AF. 1952e. Propagation of electrical signals along giant nerve fibers. Proc R Soc Lond B Biol Sci 140: $177-183$.

Hodgkin AL, Huxley AF. 1952f. A quantitative description of membrane current and its application to conduction and excitation in nerve. J Physiol 117: 500-544.

Hodgkin AL, Katz B. 1949. The effect of sodium ions on the electrical activity of giant axon of the squid. J Physiol $\mathbf{1 0 8}$ 37-77.

Hodgkin AL, Keynes RD. 1955. The potassium permeability of a giant nerve fibre. J Physiol 128: 61-88.

Hodgkin AL, Huxley AF, Katz B. 1952. Measurement of current-voltage relations in the membrane of the giant axon of Loligo. J Physiol 116: 424-448.

Holmgren M, Shin KS, Yellen G. 1998. The activation gate of a voltage-gated $\mathrm{K}^{+}$channel can be trapped in the open state by an intersubunit metal bridge. Neuron 21: 617-621. 
Hoshi T, Armstrong CM. 2013. C-type inactivation of voltage-gated $\mathrm{K}^{+}$channels: Pore constriction or dilation? Gen Physiol 141: 151-160

Hoshi T, Zagotta WN, Aldrich RW. 1990. Biophysical and molecular mechanisms of Shaker potassium channel inactivation. Science 250: 533-538.

Hoshi T, Zagotta WN, Aldrich RW. 1991. Two types of inactivation in Shaker $\mathrm{K}^{+}$channels: Effects of alterations in the carboxy-terminal region. Neuron 7: 547-556.

Islas LD, Sigworth FJ. 2001. Electrostatics and the gating pore of Shaker potassium channels. J Gen Physiol 117: 69-89.

Jensen MO, Jogini V, Borhani DW, Leffler AE, Dror RO, Shaw DE. 2012. Mechanism of voltage gating in potassium channels. Science 336: 229-233.

Jiang Y, Lee A, Chen J, Cadene M, Chait BT, MacKinnon R. 2002. Crystal structure and mechanism of a calcium-gated potassium channel. Nature 417: 515-522.

Jiang Y, Lee A, Chen J, Ruta V, Cadene M, Chait BT, MacKinnon R. 2003a. X-ray structure of a voltage-dependent $\mathrm{K}^{+}$channel. Nature 423: 33-41.

Jiang Y, Ruta V, Chen J, Lee A, MacKinnon R. 2003b. The principle of gating charge movement in a voltage-dependent $\mathrm{K}^{+}$channel. Nature 423: 42-48.

Kamb A, Tseng-Crank J, Tanouye MA. 1988. Multiple products of the Drosophila Shaker gene may contribute to potassium channel diversity. Neuron 1: 421-430.

Keynes RD, Rojas E. 1974. Kinetics and steady-state properties of the charged system controlling sodium conduc tance in the squid giant axon. J Physiol 239: 393-434.

Klein H, Garneau L, Banderali U, Simoes M, Parent L, Sauve R. 2007. Structural determinants of the closed KCa3.1 channel pore in relation to channel gating: Results from a substituted cysteine accessibility analysis. J Gen Physio 129: $299-315$

Kohout SC, Ulbrich MH, Bell SC, Isacoff EY. 2008. Subunit organization and functional transitions in Ci-VSP. Nat Struct Mol Biology 15: 106-108.

Kurata HT, Fedida D. 2006. A structural interpretation of voltage-gated potassium channel inactivation. Prog Biophys Mol Biol 92: 185-208.

Larsson HP, Baker OS, Dhillon DS, Isacoff EY. 1996. Transmembrane movement of the Shaker $\mathrm{K}^{+}$channel S4. Neuron 16: 387-397.

Latorre R, Miller C. 1983. Conduction and selectivity in potassium channels. J Membr Biol 71: 11-30.

Latorre R, Oberhauser A, Labarca P, Alvarez O. 1989. Varieties of calcium-activated potassium channels. Annu Rev Physiol 51: 385-399.

Lee SY, Lee A, Chen J, MacKinnon R. 2005. Structure of the KvAP voltage-dependent $\mathrm{K}^{+}$channel and its dependence on the lipid membrane. Proc Natl Acad Sci 102: 1544115446.

Lee SY, Letts JA, MacKinnon R. 2009. Functional reconstitution of purified human $\mathrm{Hvl} \mathrm{H}^{+}$channels. J Mol Biol 387: 1055-1060.

LeMasurier M, Heginbotham L, Miller C. 2001. KcsA: It's a potassium channel. J Gen Physiol 118: 303-314.

Li Q, Wanderling S, Paduch M, Medovoy D, Singharoy A, McGreevy R, Villalba-Galea CA, Hulse RE, Roux B,
Schulten K, et al. 2014a. Structural mechanism of voltage-dependent gating in an isolated voltage-sensing domain. Nat Struct Mol Biol 21: 244-252.

Li Q, Wanderling S, Sompornpisut P, Perozo E. 2014b. Structural basis of lipid-driven conformational transitions in the KvAP voltage-sensing domain. Nat Struct Mol Biol 21: 160-166.

Liu Y, Holmgren M, Jurman ME, Yellen G. 1997. Gated access to the pore of a voltage-dependent $\mathrm{K}^{+}$channel. Neuron 19: 175-184.

Liu S, Bian X, Lockless SW. 2012. Preferential binding of $\mathrm{K}^{+}$ ions in the selectivity filter at equilibrium explains high selectivity of $\mathrm{K}^{+}$channels. J Gen Physiol 140: 671-679.

Lockless SW, Zhou M, MacKinnon R. 2007. Structural and thermodynamic properties of selective ion binding in a $\mathrm{K}^{+}$channel. PLoS Biol 5: e121.

Long SB, Campbell EB, Mackinnon R. 2005. Crystal structure of a mammalian voltage-dependent Shaker family $\mathrm{K}^{+}$channel. Science 309: 897-903.

Long SB, Tao X, Campbell EB, MacKinnon R. 2007. Atomic structure of a voltage-dependent $\mathrm{K}^{+}$channel in a lipid membrane-like environment. Nature 450: 376-382.

Lopez-Barneo J, Hoshi T, Heinemann SH, Aldrich RW. 1993. Effects of external cations and mutations in the pore region on C-type inactivation of Shaker potassium channels. Receptor Channel 1: 61-71.

Lorinczi E, Gomez-Posada JC, de la Pena P, Tomczak AP, Fernandez-Trillo J, Leipscher U, Stuhmer W, Barros F, Pardo LA. 2015. Voltage-dependent gating of KCNH potassium channels lacking a covalent link between voltagesensing and pore domains. Nat Commun 6: 1-14

Lu Z, Klem AM, Ramu Y. 2001. Ion conduction pore is conserved among potassium channels. Nature 413 809-813.

MacKinnon R. 1991. Determination of the subunit stoichiometry of a voltage-activated potassium channel. Nature 350: $232-235$.

Mannuzzu LM, Moronne MM, Isacoff EY. 1996. Direct physical measure of conformational rearrangement underlying potassium channel gating. Science 271: $213-$ 216.

Marty A. 1981. Ca-dependent $\mathrm{K}$ channels with large unitary conductance in chromaffin cell membranes. Nature 291 497-500.

Matsuda M, Takeshita K, Kurokawa T, Sakata S, Suzuki M, Yamashita E, Okamura Y, Nakagawa A. 2011. Crysta structure of the cytoplasmic phosphatase and tensin homolog (PTEN)-like region of Ciona intestinalis voltagesensing phosphatase provides insight into substrate specificity and redox regulation of the phosphoinositide phosphatase activity. J Biol Chem 286: 23368-23377.

McCoy JG, Nimigean CM. 2012. Structural correlates of selectivity and inactivation in potassium channels. Biochim Biophys Acta 1818: 272-285.

Molina A, Castellano AG, Lopez-Barneo J. 1997. Pore mutations in Shaker $\mathrm{K}^{+}$channels distinguish between the sites of tetraethylammonium blockade and C-type inactivation. J Physiol 499: 361-367.

Mullins LJ. 1959. An analysis of conductance changes in squid axon. J Gen Physiol 42: 1013-1035. 
D.M. Kim and C.M. Nimigean

Murata Y, Iwasaki H, Sasaki M, Inaba K, Okamura Y. 2005. Phosphoinositide phosphatase activity coupled to an intrinsic voltage sensor. Nature 435: 1239-1243.

Neher E, Sakmann B. 1975. Voltage-dependence of druginduced conductance in frog neuromuscular junction. Proc Natl Acad Sci 72: 2140-2144.

Neyton J, Miller C. 1988a. Discrete $\mathrm{Ba}^{2+}$ block as a probe of ion occupancy and pore structure in the high-conductance $\mathrm{Ca}^{2+}$-activated $\mathrm{K}^{+}$channel. J Gen Physiol 92: 569586.

Neyton J, Miller C. 1988b. Potassium blocks barium permeation through a calcium-activated potassium channel. $J$ Gen Physiol 92: 549-567.

Noda M, Takahashi H, Tanabe T, Toyosato M, Furutani Y, Hirose T, Asai M, Inayama S, Miyata T, Numa S. 1982. Primary structure of $\alpha$-subunit precursor of Torpedo californica acetylcholine receptor deduced from cDNA sequence. Nature 299: 793-797.

Noda M, Takahashi H, Tanabe T, Toyosato M, Kikyotani S, Hirose T, Asai M, Takashima H, Inayama S, Miyata T, et al. 1983. Primary structures of $\beta$ - and $\delta$-subunit precursors of Torpedo californica acetylcholine receptor deduced from cDNA sequences. Nature 301: 251-255.

Noda M, Shimizu S, Tanabe T, Takai T, Kayano T, Ikeda T, Takahashi H, Nakayama H, Kanaoka Y, Minamino N, et al. 1984. Primary structure of Electrophorus electricus sodium channel deduced from cDNA sequence. Nature 312: $121-127$

Noskov SY, Berneche S, Roux B. 2004. Control of ion selectivity in potassium channels by electrostatic and dynamic properties of carbonyl ligands. Nature 431: 830-834.

Ostmeyer J, Chakrapani S, Pan AC, Perozo E, Roux B. 2013. Recovery from slow inactivation in $\mathrm{K}^{+}$channels is controlled by water molecules. Nature 501: 121-124.

Papazian DM, Schwarz TL, Tempel BL, Jan YN, Jan LY. 1987. Cloning of genomic and complementary DNA from Shaker, a putative potassium channel gene from Drosophila. Science 237: 749-753.

Pardo LA, Heinemann SH, Terlau H, Ludewig U, Lorra C, Pongs O, Stuhmer W. 1992. Extracellular $\mathrm{K}^{+}$specifically modulates a rat brain $\mathrm{K}^{+}$channel. Proc Natl Acad Sci 89: 2466-2470.

Pathak MM, Yarov-Yarovoy V, Agarwal G, Roux B, Barth P, Kohout S, Tombola F, Isacoff EY. 2007. Closing in on the resting state of the Shaker $\mathrm{K}^{+}$channel. Neuron 56: 124-140.

Payandeh J, Scheuer T, Zheng N, Catterall WA. 2011. The crystal structure of a voltage-gated sodium channel. $\mathrm{Na}$ ture 475: 353-358.

Payandeh J, Gamal El-Din TM, Scheuer T, Zheng N, Catterall WA. 2012. Crystal structure of a voltage-gated sodium channel in two potentially inactivated states. Nature $\mathbf{4 8 6}$ : 135-139.

Perozo E, MacKinnon R, Bezanilla F, Stefani E. 1993. Gating currents from a nonconducting mutant reveal openclosed conformations in Shaker $\mathrm{K}^{+}$channels. Neuron 11: 353-358.

Pongs O, Kecskemethy N, Muller R, Krah-Jentgens I, Baumann A, Kiltz HH, Canal I, Llamazares S, Ferrus A. 1988 Shaker encodes a family of putative potassium channel proteins in the nervous system of Drosophila. EMBO J 7: 1087-1096.

Posson DJ, Ge P, Miller C, Bezanilla F, Selvin PR. 2005. Small vertical movement of a $\mathrm{K}^{+}$channel voltage sensor measured with luminescence energy transfer. Nature 436: 848-851.

Posson DJ, McCoy JG, Nimigean CM. 2013. The voltagedependent gate in MthK potassium channels is located at the selectivity filter. Nat Struct Mol Biol 20: 159-166.

Posson DJ, Rusinova R, Andersen OS, Nimigean CM. 2015. Calcium ions open a selectivity filter gate during activation of the MthK potassium channel. Nat Commun 6: 8342.

Ramsey IS, Moran MM, Chong JA, Clapham DE. 2006. A voltage-gated proton-selective channel lacking the pore domain. Nature 440: 1213-1216.

Ramu Y, Xu Y, Lu Z. 2006. Enzymatic activation of voltagegated potassium channels. Nature 442: 696-699.

Rettig J, Heinemann SH, Wunder F, Lorra C, Parcej DN, Dolly JO, Pongs O. 1994. Inactivation properties of voltage-gated $\mathrm{K}^{+}$channels altered by presence of $\beta$-subunit. Nature 369: 289-294.

Ruta V, Chen J, MacKinnon R. 2005. Calibrated measurement of gating-charge arginine displacement in the KvAP voltage-dependent $\mathrm{K}^{+}$channel. Cell 123: 463-475.

Sandblom J, Eisenman G, Neher E. 1977. Ionic selectivity, saturation and block in gramicidin A channels. I: Theory for the electrical properties of ion selective channels having two pairs of binding sites and multiple conductance states. J Membr Biol 31: 383-347.

Sasaki M, Takagi M, Okamura Y. 2006. A voltage sensordomain protein is a voltage-gated proton channel. Science 312: 589-592.

Schmidt D, Jiang QX, MacKinnon R. 2006. Phospholipids and the origin of cationic gating charges in voltage sensors. Nature 444: 775-779.

Schneider MF, Chandler WK. 1973. Voltage dependent charge movement of skeletal muscle: a possible step in excitation-contraction coupling. Nature 242: 244-246.

Schoppa NE, McCormack K, Tanouye MA, Sigworth FJ. 1992. The size of gating charge in wild-type and mutant Shaker potassium channels. Science 255: 1712-1715.

Seoh SA, Sigg D, Papazian DM, Bezanilla F. 1996. Voltagesensing residues in the S2 and S4 segments of the Shaker $\mathrm{K}^{+}$channel. Neuron 16: 1159-1167.

Starace DM, Bezanilla F. 2001. Histidine scanning mutagenesis of basic residues of the S4 segment of the Shaker $\mathrm{K}^{+}$ channel. J Gen Physiol 117: 469-490.

Starace DM, Bezanilla F. 2004. A proton pore in a potassium channel voltage sensor reveals a focused electric field. Nature 427: 548-553.

Takeuchi K, Takahashi H, Kawano S, Shimada I. 2007. Identification and characterization of the slowly exchanging $\mathrm{pH}$-dependent conformational rearrangement in KcsA.J Biol Chem 282: 15179-15186.

Tang QY, Zeng XH, Lingle CJ. 2009. Closed-channel block of BK potassium channels by bbTBA requires partial activation. J Gen Physiol 134: 409-436.

Tempel BL, Papazian DM, Schwarz TL, Jan YN, Jan LY. 1987. Sequence of a probable potassium channel compo- 
nent encoded at Shaker locus of Drosophila. Science 237: $770-775$.

Thompson J, Begenisich T. 2012. Selectivity filter gating in large-conductance $\mathrm{Ca}^{2+}$-activated $\mathrm{K}^{+}$channels. J Gen Physiol 139: 235-244.

Thompson AN, Posson DJ, Parsa PV, Nimigean CM. 2008. Molecular mechanism of $\mathrm{pH}$ sensing in KcsA potassium channels. Proc Natl Acad Sci 105: 6900-6905.

Thompson AN, Kim I, Panosian TD, Iverson TM, Allen TW Nimigean CM. 2009. Mechanism of potassium-channel selectivity revealed by $\mathrm{Na}^{+}$and $\mathrm{Li}^{+}$binding sites within the KcsA pore. Nat Struct Mol Biol 16: 1317-1324.

Vargas E, Yarov-Yarovoy V, Khalili-Araghi F, Catterall WA, Klein ML, Tarek M, Lindahl E, Schulten K, Perozo E, Bezanilla F, et al. 2012. An emerging consensus on voltage-dependent gating from computational modeling and molecular dynamics simulations. J Gen Physiol 140: 587-594.

Villalba-Galea CA, Sandtner W, Starace DM, Bezanilla F 2008. S4-based voltage sensors have three major conformations. Proc Natl Acad Sci 105: 17600-17607.

Wilkens CM, Aldrich RW. 2006. State-independent block of BK channels by an intracellular quaternary ammonium. $J$ Gen Physiol 128: 347-364.

Xu Y, Ramu Y, Lu Z. 2008. Removal of phospho-head groups of membrane lipids immobilizes voltage sensors of $\mathrm{K}^{+}$ channels. Nature 451: 826-829.

Yang N, George AL Jr, Horn R. 1996. Molecular basis of charge movement in voltage-gated sodium channels. Neuron 16: 113-122.

Yang Y, Yan Y, Sigworth FJ. 1997. How does the W434F mutation block current in Shaker potassium channels? J Gen Physiol 109: 779-789.

Yarov-Yarovoy V, Baker D, Catterall WA. 2006. Voltage sensor conformations in the open and closed states in ROSETTA structural models of $\mathrm{K}^{+}$channels. Proc Natl Acad Sci 103: $7292-7297$.

Yarov-Yarovoy V, DeCaen PG, Westenbroek RE, Pan CY, Scheuer T, Baker D, Catterall WA. 2012. Structural basis for gating charge movement in the voltage sensor of a sodium channel. Proc Natl Acad Sci 109: E93-E102.

Yellen G. 1984. Ionic permeation and blockade in $\mathrm{Ca}^{2+}$ activated $\mathrm{K}^{+}$channels of bovine chromaffin cells. J Gen Physiol 84: 157-186.

Zagotta WN, Hoshi T, Aldrich RW. 1990. Restoration of inactivation in mutants of Shaker potassium channels by a peptide derived from ShB. Science 250: $568-571$.

Zhang X, Ren W, DeCaen P, Yan C, Tao X, Tang L, Wang J, Hasegawa K, Kumasaka T, He J, et al. 2012. Crystal structure of an orthologue of the NaChBac voltage-gated sodium channel. Nature 486: 130-134.

Zheng H, Liu W, Anderson LY, Jiang QX. 2011. Lipid-dependent gating of a voltage-gated potassium channel. Nat Commun 2: 250.

Zhou Y, MacKinnon R. 2004. Ion binding affinity in the cavity of the KcsA potassium channel. Biochemstry 43: 4978-4982.

Zhou M, Morais-Cabral JH, Mann S, MacKinnon R. 2001a. Potassium channel receptor site for the inactivation gate and quaternary amine inhibitors. Nature 411: 657-661.

Zhou Y, Morais-Cabral JH, Kaufman A, MacKinnon R. 2001b. Chemistry of ion coordination and hydration revealed by a $\mathrm{K}^{+}$channel-Fab complex at $2.0 \AA$ resolution. Nature 414: 43-48.

Zhou Y, Xia XM, Lingle CJ. 2011. Cysteine scanning and modification reveal major differences between BK channels and $\mathrm{Kv}$ channels in the inner pore region. Proc Natl Acad Sci 108: 12161-12166. 


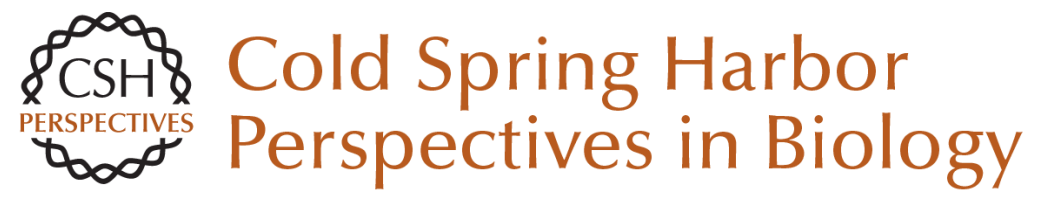

\section{Voltage-Gated Potassium Channels: A Structural Examination of Selectivity and Gating}

Dorothy M. Kim and Crina M. Nimigean

Cold Spring Harb Perspect Biol 2016; doi: 10.1101/cshperspect.a029231

Subject Collection

For additional articles in this collection, see http://cshperspectives.cshlp.org/cgi/collection/

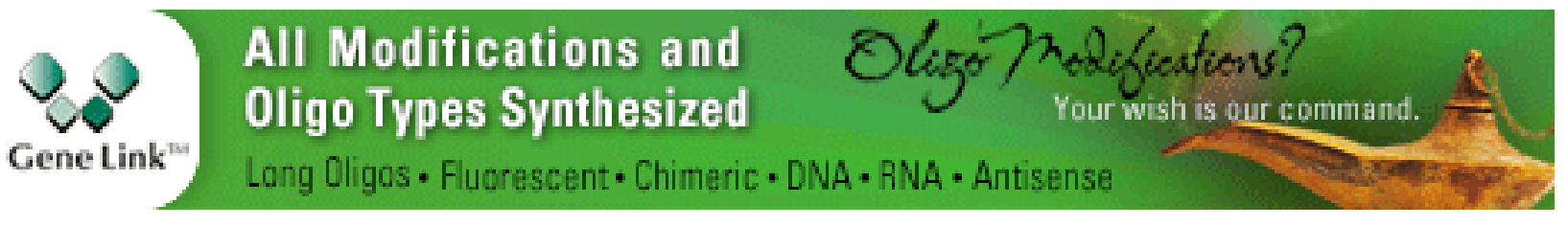

Copyright @ 2016 Cold Spring Harbor Laboratory Press; all rights reserved 